\title{
Dual-hub connectivity: a case study on China Eastern Airlines in Shanghai
}

\author{
Huijuan Yang ${ }^{*}$ (D) and Weiwei Liu
}

\begin{abstract}
To deal with slot constraints and insufficient capacity, emerging multi-airport systems have been under construction in China. This paper chose China Eastern Airlines as a case study, evaluating its hub connectivity under a dual-hub circumstance in Shanghai. The paper detected that the biggest constraint of China Eastern Airlines' dual-hub situation lied in Shanghai's location and the restricted transfer options on international routes. Contributions from alliance partners were assessed and benchmarked with China Eastern Airlines. With China Southern Airlines quit SkyTeam alliance, China Eastern Airlines faced more challenges on the domestic market. The empirical study also pointed out the shortcoming of operating at two hubs in the same catchment area, where the quality of connectivity of inter-hub connections cannot be maintained as high as a single-hub transfer. However, the market potential of inter-hub connections in Shanghai was identified with a considerable amount of viable connections.
\end{abstract}

Keywords: Hub connectivity, Dual-hub operation, China Eastern Airlines

\section{Introduction}

Airports have experienced pressures on operational capacity and congestion due to the worldwide effects of explosive passenger growth, particularly in high-growth regions such as Southeast Asia, China, and India [1]. In response to sustained passenger growth, airports have invested in the expansion of existing infrastructures, such as new runways and terminals. For example, the United States has added 18 new runways and extended 7 runways at 21 busy hub airports during the past 15 years [11]. Although studies recommend expanding capacity through slot reallocation and expansion infrastructures as the primary option, it leads to enormous capital investment, projected flight delays, public outcry, and environmental concerns [19]. More importantly, it will be no longer feasible at certain airports [5, 27]. FAA predicts that 9 airports will be congested by 2030 even after the implementation of the NextGen air traffic management initiatives and runway improvements [11]. Consequently, secondary airports and multi-airport systems are emerging worldwide to provide additional capacity for world-class metropolitan cities, such as New York, London, Paris, Tokyo and Shanghai.

\footnotetext{
* Correspondence: hyang@cafuc.edu.cn

Civil Aviation Flight University of China, Guanghan, Sichuan Province 618300, People's Republic of China
}

Multi-airport system largely expands the catchment area and capacity in the region. It provides better accessibility for passengers, and attracts and generates more traffic for airlines and airports. Particularly, the catchment area can be further enlarged with the development of High-speed Rail (HSR). By connecting airports with direct HSR links, the HSR contributes to the catchment area of international hubs and play a significant role in the reorganization of the multi-airport systems [7]. A typical multi-airport system consists of a major international hub operated by full service carriers, and one (or more) secondary hub focuses on domestic, regional and commuter traffic, mainly serving low cost carriers [17]. Subsequently, the resource allocation and conflicts of nearby hubs become inherent problems for multi-airport system [5]. Due to capacity or slots limits, full service carrier may operate at both primary and secondary airports in a vicinity area to build a dual-hub configuration. For example, British Airways builds its hubs in London Heathrow and Gatwick Airport, while Air France operates in Paris Charles de Gaulle and Orly Airport. Likewise, All Nippon Airways locates its main hubs at two Tokyo airports (Narita and Haneda), serving International and domestic passengers, respectively. Thus, the smaller hub inevitably becomes more vulnerable than the primary hub. For instance, London Gatwick adjusted 2744 connections (79\%) due to British Airways' network restructuring 
[20]. Likewise, other threatens may come from the network reorganisation of the three major global alliances (SkyTeam, Star Alliance and Oneworld) [20]. Moreover, the dual-hub configuration also challenges legacy airlines' operation. One major concern of airlines is the ground transfer among airports for connecting flights, which poses challenges in terms of convenience and duration.

This research is designed to provide a theoretical and empirical reference, and deliver a measurable approach to dual-hub connectivity. In pursuing the aim of the study, China Eastern Airlines, the largest participant in Shanghai, is chosen as the subject of this case study which measures its connectivity under a dual-hub configuration. The structure of this research has been identified: previous literature and methodology are introduced and specified in section 2 and 3; section 4 and 5 takes China Eastern Airlines as the subject of this case study, presenting and benchmarking their connectivity in Pudong and Hongqiao against its SkyTeam alliance partners; last but not the least, key findings are summarised and conclusions are drawn in section 6 .

\section{Literature review}

Quite a few studies have focused on the issue of hub airport connectivity. Hub connectivity and its strategic role in network performance could be assessed by different methodologies for different purposes. Generally, it refers to the quantitative and qualitative level of reasonable indirect connections offered through the assessed airline hub [2]. By co-ordinating flight schedules, airline managers enhance airline hub connectivity without increasing the number of flights. Therefore, a quantitative evaluate of hub schedule co-ordination measures the degree to which it contributes to hub connectivity [9]. It proposes insight not only to the competitive position or the connectivity premium of an airport or airline, but also to the scale of available connecting options to passengers.

Studies have identified the parameters that affect both quantity and quality of hub connections to tackle hub connectivity from a methodological perspective. A well-known and frequently used approach is the network quality model, which incorporates routing factors and minimum and maximum connecting times and identifies hub connections that are available for a defined period of time. Doganis and Dennis [10] introduced the concept of connectivity ratio, and provided the foundation of this method with 'Hub Potential' and 'Connectivity' models for European airlines. However, their work primarily targeted at the quantity of connectivity by applying minimum connecting time to flight schedule data. Veldhuis [23] proposed the 'NetScan' model, applying weights to potential flight combinations and performing a quality-weighted indicator to calculate the number of connectivity units. In his work, the connectivity of Amsterdam Airport was analysed, together with its position in markets within Europe, and on routes between Europe and the rest of the world. Burghouwt and de Wit [3] proposed "weighted indirect connection number" to measure hub connectivity in both quality and quantity manner, and applied to European airlines. Following this stream, Matsumoto et al. [18] evaluated the network performance and hub connectivity of the thirteen primary airports in East and Southeast Asia, and identified the largest hub connectivity in Tokyo and the highest growth in network development in Beijing, Shanghai and Guangzhou. Meanwhile, other scholars identified Hong Kong as the most connected hub airport in this region [12]. Following these studies, Huang and Wang [13] compared the indirect connectivity for top 10 Chinese airports between 2010 and 2015. Although this paper outlined that Pudong and Hongqiao airports maximize the spatial coverage of Shanghai, it failed to identify the challenges from split traffic between two airports in the same catchment area.

In relation to multi-hub airline operations, $\mathrm{Li}$ et al. [15] focused their research on Japan, and examined the dual-hub network connectivity of All Nippon Airways at Tokyo's Haneda and Narita airports, supposing a reduction of network connectivity for ANA compared to regional competitors. ITF [14] evaluated the multi-airport systems in New York, Tokyo, Osaka and in Germany. This research also claimed that the split operations by the hub carrier and its partners become a major drawback to maximising the benefits of hub connectivity.

The remarkable period of rapid growth in China has witnessed the emergence of airline networks and airport hubs [8]. Operating approximately 2000 daily flights, Shanghai's two mega-airports surpassed Beijing Capital International Airport, making Shanghai the best-connected city in 2016 [25]. However, no known study has analysed airlines' network under dual-hub connectivity in China. This paper aims to explore this region with a case study of China Eastern Airlines in Shanghai.

\section{Methods}

The hub connectivity will be answered by the Hub Connectivity Index (HCI) modified based on the previous study [15].

\subsection{Quantity of connectivity}

The quantity of hub connectivity is usually defined by the number of viable connections, indicating the maximum number of connections within the Minimum Connecting Time (MCT) and the Maximum Acceptable Connecting Time (MACT). A pair of arriving and departing flights, which can be connected within MCT and MACT, is defined as a viable connection. Hence, the sum of all viable connections denotes as the Quantity of Viable Connections (QVC), measuring the number of all possible connecting flights based on the airline schedule. A larger QVC represents more connecting opportunities 
for passengers within a time window. The calculation process can be expressed by Eq. (1), where $n$ denotes the total number of inbound flights during the research period. The MCT values in this study were directly sourced from China Eastern Airlines. To maintain the consistency of previous studies, this study selects three times of corresponding MCT as the MACT, as summarised by Table $1{ }^{1}$

$$
\mathrm{QVC}=\sum_{1}^{\mathrm{n}} \text { viable connection }
$$

In terms of inter-hub ground transport, the direct services by taxi/coach take approximately 60-90 min (depends on the traffic) via highway. An extra 15-30 min may be necessary for passengers travelling by coach for ticketing and waiting for departure. Currently, there is no direct service from rail/underground. The whole journey by underground takes roughly $120 \mathrm{~min}$, while a combination of maglev and underground only takes $60 \mathrm{~min}$. Although inter-hub ground travel is time-consuming, it can be estimated and prepared before booking air tickets. Thus, this study only considers ideal inter-hub transfers costing $60 \mathrm{~min}$, and excludes the possibility of missing connections due to ground delay. Li et al. [15] excluded international-international inter-hub connection due to custom and immigration requirement. However, the quantity and quality of international-international connections indicate the passenger appealing and the airport potential to become an international gateway. Although the MCT on internationalinternational routes via Shanghai is not as competitive as those Middle East airports, it is still worthwhile to fill this gap [16].

\subsection{Quality of connectivity}

Quality of Connectivity Index (QCI) refers to a weighted indirect connection number calculated for a pair of connecting flights. Previous studies proposed many alternative approaches to weight the viable connections in both time and routing manner $[3,9]$. To maintan the consistency of studies regarding dual-hub configuration, this study adopted and modified the method presented by $\mathrm{Li}$ et al. [15]. In this sense, the QCI addresses the value and market appeal of viable connections, calculated by Time Factor (TF) multiplying Routing Factor (RF). TF demonstrates the quality of a transfer option by benchmarking the travel time of direct flight against perceived travel flight. A higher TF reveals the more attractiveness of a transfer flight. As described in Eq. (2), the direct flight time is estimated based on the great circle distance between two connecting points (the first segment's origin airport and the second segment's destination airport). Li et al. [15] applied a penalty factor to the transfer time to measure passenger experiences by the availability of direct flights and the involvement of inter-hub transfer. However, the transfer time in Eq. (2) denotes the schedule connecting time between two flights (from the arrival time of the first segment to the departure of the second flight). While the penalty factor in the previous study refers to the convenience of ground transfer, passenger feelings do not impact either the ground travel time or the total perceived flight time. Therefore, it is removed in this research.

$$
\mathrm{TF}=\frac{\text { estimated direct flight time }}{\text { flight time of two segments }+ \text { transfer time }}
$$

RF is quantified by the Detour Index, which can be estimated with connecting flights' great circle distance

\begin{tabular}{|c|c|c|c|}
\hline & Type of Connection & Minimum (MCT) & Maximum (MACT) \\
\hline \multirow[t]{4}{*}{ Single Hub (Same Terminal) } & Domestic - Domestic & 45 & 135 \\
\hline & Domestic - International & 90 & 270 \\
\hline & International - Domestic & 90 & 270 \\
\hline & International - International & 120 & 360 \\
\hline \multirow[t]{4}{*}{ Single Hub (Different Terminal) } & Domestic - Domestic & 75 & 165 \\
\hline & Domestic - International & 120 & 300 \\
\hline & International - Domestic & 120 & 300 \\
\hline & International - International & 150 & 390 \\
\hline \multirow[t]{4}{*}{ Inter-Hub Transfer } & Domestic - Domestic & 150 & 450 \\
\hline & Domestic - International & 180 & 540 \\
\hline & International - Domestic & 180 & 540 \\
\hline & International - International & 180 & 540 \\
\hline
\end{tabular}

Table 1 Minimum and maximum connecting time for China Eastern Airlines in Pudong and Hongqiao 
divided by that of non-stop flights. The smaller the Detour Index is, the more appealing it is to passengers. RF zeros out any Detour Index in excess of 1.5, where a transfer option loses its attractiveness to passengers due to detour or backtracking. When Detour Index is less than or equal to 1.2 , RF is quantified as 1 , indicating the most appeal transfer connection; otherwise, RF is quantified as 0.5 .

Since both TF and RF are either less than or equal to 1, the QCI is an integer ranging from 0 to 1 . Based on the equations, only non-stop flight obtains 1 as its QCI, while the QCI of an indirect connection will always be lower than 1 due to extra travel time and detour. Last but not the least, it is important to clarify that the QCI of appeal connections will probably be magnified due to the Multiplier Effect. This is because transfer options with smaller RF usually require less flight time, ceteris paribus.

\subsection{Hub connectivity Indicator}

Previous studies consider frequency as one of the most important indicators for hub connectivity $[4,15]$. However, the weekly frequency is taken into account by the mechanism when weekly data applies, where QVC and QCI are evaluated for all possible connecting opportunities during each day of the week. Subsequently, the Hub Connectivity Indicator ( $\mathrm{HCI}$ ) is derived by summing the quality of all viable connections as illustrated in Eq. (3) [16]. The absolute value of HCI refers to the number of equivalent direct flights via hub airports.

$$
\mathrm{HCI}=\sum_{1}^{Q V C} Q C I
$$

The primary data required for modelling is from VariFlight, ${ }^{2}$ including flight schedule information, such as origin, destination, departure and arrival time, as well as operating airline. Seasonality shows that carriers schedule more flights in August to/from Shanghai. Hence, this research deploys data from the first week of August 2016 as a representative week in the schedule. The great circle distance is calculated with the altitude and latitude of each airport to estimate the routing factor and direct flight time.

\section{Dual-hub configuration in Shanghai}

Shanghai became the first city with two international airports in China in 1999. Pudong International Airport (PVG) mainly functions as an international gateway, where $43 \%$ of approximately 1250 daily flights are international ones. ${ }^{3}$ It locates $30 \mathrm{~km}$ east of the city centre, serving as the main hub of China Eastern Airlines (MU) and its subsidiary (Shanghai Airlines, IATA code: FM), a major international hub of Air China (CA), as well as the secondary hub of China Southern Airlines (CZ).
China Eastern Airlines and Shanghai Airlines take the largest market share in Pudong, holding 29\% and 10\% of slots. Compared to the $39 \%$ of slots held by China Eastern Airlines and its subsidiary, no other carrier holds more than 10\%. Air China and China Southern Airlines hold $7 \%$ and $9 \%$, respectively, while the remaining slots are held by other domestic and international carriers. Hongqiao International Airport (SHA) operates over 700 flights per day, 94\% of which are domestic ones. ${ }^{4} \mathrm{Al}$ though Hongqiao is the smaller hub in Shanghai, China Eastern Airlines and Shanghai Airlines establish a stronger market power, holding $30 \%$ and $20 \%$ of slots. Located $13 \mathrm{~km}$ west of downtown, Hongqiao seems to be more convenient for domestic passengers.

After continuous deregulation in China, the market mechanism for slot allocations are introduced to further enhance the connectivity in Shanghai under scarce airport capacities [25]. To maintain competitiveness with other airlines, more than 25 airlines utilize both Pudong and Hongqiao. That not only complicates airlines' slots coordination strategies, but also indicates significant switching costs from reallocating capacity between airports. While it is not commercially feasible for airlines to operate short connecting flights between Hongqiao and Pudong, the $60 \mathrm{~km}$ inter-hub transfer poses another challenge to airlines' connectivity under the dual-hub circumstance.

\section{Results and discussion}

\subsection{Overall hub connectivity}

Code-sharing and partnerships are common methods for airlines to obtain better resources at airports under market-driven consolidation [13]. The merger of China Eastern Airlines and Shanghai Airlines was completed in 2010 to reduce excess competition between those two Shanghai-based carriers while consolidating Shanghai's status as an international aviation hub. Although operating as a wholly owned subsidiary of China Eastern Airlines, Shanghai Airlines retains its brand and livery. Therefore, it will be analysed separately and then aggregated as a group (MU Group).

Table 2 presents the overall connectivity of MU Group under a dual-hub network. In 2016, MU Group offered 192,470 viable connections in a week, representing approximately 25,500 daily connections on average. However, the overall HCI of MU Group limited to 42,083, which equals to 6000 non-stop flights each day. In other words, less than $22 \%$ of those variable connections created the equivalent connecting opportunities as direct flights. Since only connections with positive QCI are considered appealing to passengers, $46 \%$ of the Group's viable connections were useless, due to either prolonged transfer time or substantial backtracking. The reasons behind this can be diagnosed by market breakdown, 
Table 2 MU Group's hub connectivity

\begin{tabular}{lllll}
\hline & Airline & QVC & HCl & Viable Connections (with QCl >0) \\
\hline Overall Connections & MU Group & 192,470 & 42,083 & 103,866 \\
& MU & 98,866 & 24,134 & 56,947 \\
Domestic Connections & FM & 16,105 & 2327 & 6729 \\
& MU Group & 91,213 & 8524 & 30,023 \\
International Connections & MU & 41,235 & 3659 & 12,903 \\
& FM & 10,333 & 1094 & 3547 \\
& MU Group & 101,257 & 33,559 & 73,843 \\
\hline
\end{tabular}

Source: Compiled by authors

where domestic transfers became the shortfalls of $\mathrm{MU}$ Group. With similar contributions in QVC (91,213 for domestic and 101,257 for international), only 33\% of domestic flights had positive QCIs, providing $20 \%$ of the total $\mathrm{HCI}$. The superior performance of international connections seemed to be a natural consequence of Shanghai's geographic location. Although airports in China are heavily connected with and circled around Shanghai, most of the domestic passengers experience prolonged detour transferring via the east-coast part of China [24]. Therefore, Shanghai's hub position on domestic connecting flights remained uncertain, although previous studies show that Shanghai obtained the highest connectivity on both domestic and international markets $[25,26]$.

In general, MU performed better than its subsidiary under the dual-hub circumstance. MU contributed more than half of the group's QVC and HCI, and provided a majority part of the rest via connecting flights operated with FM. This resulted from the operation scale of FM, which mainly targeted at the mainland of China with limited international flights to Hong Kong, Macau, Taiwan, Japan, South Korea, Indonesia, Singapore, Thailand and Australia. Table 2 confirms the relative strong competitive edge of FM on domestic routes with higher proportion of connections with positive QCI.

MU Group became a member of SkyTeam in 2011. Alliance partners improved the quantity of viable connections by $66 \%$ with a competitive quality, maintaining the overall HCI level with MU Group. ${ }^{5}$ Table 3 also illustrates that MU Group benefited a lot from the strong network of China Southern Airlines (CZ) and its subsidiary (Xiamen Airlines, IATA code: MF) on domestic market. Sharing the same terminal with MU and FM for domestic flights in Hongqiao, CZ and MF offered shorter MCT and walking distance to connecting passengers, overcompensating MU Group network by enhancing the density considerably. However, with China Southern Airlines Group left SkyTeam in 2019, MU Group lost its one and the only alliance partner on domestic market, together with 78\% of QVC and 65\% of HCI [22]. Meanwhile, other international partners can only contribute on routes, where international flights are involved. This is because the Eights Freedom (consecutive cabotage) does not applied in China.

\subsection{Dual-hub connectivity}

The partnership with CZ Group largely strengthened MU Group's domestic network on north-south direction with competitive HCI, such as DLC-PVG/SHA-CAN and SZXPVG/SHA-PEK. ${ }^{6}$ Although west-east directional flights were involved in the inter-hub connections, their $\mathrm{HCI}$ were relatively low due to detour. For example, 295 connections

Table 3 SkyTeam partners' contributions (by carrier)

\begin{tabular}{llll}
\hline Airline & QVC & $\mathrm{HCl}$ & Viable Connections (with QCl > 0) \\
\hline CZ & 83,196 & 14,847 & 39,837 \\
Domestic & 54,765 & 6405 & 20,602 \\
International & 28,431 & 8443 & 19,235 \\
MF & 16,968 & 3485 & 9484 \\
$\quad$ Domestic & 9673 & 1351 & 4470 \\
International & 7295 & 2134 & 5014 \\
KE & 5883 & 1596 & 3979 \\
Cl & 5011 & 1069 & 3281 \\
VN & 3667 & 706 & 1797 \\
DL & 3379 & 2108 & 3153 \\
KL & 2789 & 1388 & 2644 \\
AF & 2659 & 1260 & 2424 \\
SU & 2076 & 770 & 1910 \\
GA & 1754 & 546 & 1212 \\
AM & 544 & 326 & 510 \\
Overall & 127,926 & 28,102 & 70,231
\end{tabular}

Notes: Only connections involving one segment operated by partners are counted; notation CZ (China Southern Airlines), MF (Xiamen Airlines), KE (Korean Air), Cl (China Airlines), VN (Vietnam Airlines), DL (Delta Airlines), KL (KLM Royal Dutch Airlines), AF (Air France), SU (Aeroflot) and GA (Garuda Indonesia), AM (Aeroméxico)

Source: Compiled by authors 
from XIY to XMN with a transfer form Pudong to Hongqiao only achieved 42.26 in HCI. The route $\mathrm{HCI}$ dropped to zero when it came to CTU-PVG/SHA-XMN.?

It is also noticeable that inter-hub connections tremendously enriched passengers choices by offering more opportunities to connect. For instance, a single hub transfer via Pudong only provided 56 combinations on routes from DLC to CAN, while an inter-hub transfer offered 445 connections with the same quality (HCI). However, those flights were with strong directionality due to the split traffic under dual-hub configuration. In other words, passengers can only fly to/from DLC via Pudong instead of Hongqiao.

Although inter-hub connections obtained the largest QVC among different airline transfer combinations on domestic market, the lowest HCI illustrated its least appealing to passengers since inter-hub transfer and ground waiting time could be longer than the flight time of one or two segments. Overall, single hub transfers via Pudong were more efficient and convenient for passengers with more viable connections with positive QVC on both domestic and international routes. More precisely, MU Group demonstrated its home advantage on the international market via Pudong, while single hub transfer via Hongqiao lost its competitiveness with the lowest QVC and HCI (see Table 4).

The competitive $\mathrm{HCI}$ among all the international transfers presented the crucial position of Shanghai in connecting the east to the west part of the world. As demonstrated in Table 5, MU Group and its partners served 18,525 and 20,002 connecting flights weekly to/from North America and Europe, respectively. The higher HCI $(11,493)$ on North America routes came from less detour compared with backtracking to Europe (9887). Intra-Asia routes obtained a relative small number of viable connections with positive QVC, because of Shanghai's geographic position on the periphery of Asia. However, the large amount of intra-Asian connections indicated their stimulus for the hub airport connectivity [12]. International-international connections became MU Group and its partners' weak spot in Shanghai, providing the lowest QVC and HCI. Therefore, hub airlines in Shanghai need to pay close attention to those international transfers, to fulfil its goal of becoming an international gateway in China.

Additionally, Table 5 takes bi-directionality of connections into account, as it guarantees the existence of the return flight for every viable connection within one week [16]. The connections via Shanghai showed strong directionality for both single hub transfers and inter-hub ones. For example, flights from Europe to Asia obtained over 40 transfer options via Shanghai, while the number dropped to 3 in the opposite direction. This outcome resulted from the limited proportion of flights from Shanghai to Europe, contributing only $1.4 \%$ of total flights, whereas $92.8 \%$ of slots connected Shanghai with Asia cities. Precisely, MU and SkyTeam partners only operated 98 out of 191 flights from Shanghai to Europe on a weekly basis, which led to the lack of options for the considerable amount of flights within Asia. Similar results were also found in Australasia and America market.

Shanghai Government [21] claims that Pudong and Hongqiao International Airports will serve for 160-180 million passengers annually by $2040,40 \%$ of which will be international travelers. In other words, airlines in Shanghai will continue operating under the dual-hub configuration in the long run. Shanghai Master Plan 2040 [21] also considers rapid rail services as the ultimate solution for fast and frequent transit between Pudong and Hongqiao. Yet, the construction is expensive and time-consuming, airlines and passengers will

Table 4 Dual-hub connectivity of MU Group and alliance partners

\begin{tabular}{|c|c|c|c|c|c|c|c|c|c|c|}
\hline & & \multicolumn{3}{|l|}{ PVG } & \multicolumn{3}{|c|}{ Inter-hub } & \multicolumn{3}{|l|}{ SHA } \\
\hline & & QVC & $\mathrm{HCl}$ & $\begin{array}{l}\text { Viable Connections } \\
\text { (with } \mathrm{QCl}>0 \text { ) }\end{array}$ & QVC & $\mathrm{HCl}$ & $\begin{array}{l}\text { Viable Connections } \\
\text { (with } \mathrm{QCl}>0 \text { ) }\end{array}$ & QVC & $\mathrm{HCl}$ & $\begin{array}{l}\text { Viable Connections } \\
\text { (with } \mathrm{QCl}>0 \text { ) }\end{array}$ \\
\hline \multirow[t]{5}{*}{ Domestic } & $\mathrm{MU}$ & 6715 & 890 & 2394 & 27,601 & 1989 & 8381 & 6919 & 781 & 2128 \\
\hline & FM & 1469 & 267 & 608 & 6795 & 556 & 2235 & 2069 & 270 & 704 \\
\hline & MU-FM & 5907 & 890 & 2334 & 27,612 & 2175 & 9150 & 6126 & 706 & 2089 \\
\hline & MU Group & 14,091 & 2047 & 5336 & 62,008 & 4719 & 19,766 & 15,114 & 1758 & 4921 \\
\hline & $\begin{array}{l}\text { MU Group + Alliance } \\
\text { Partners }\end{array}$ & 24,363 & 3729 & 9679 & 110,145 & 9937 & 38,753 & 25,573 & 3301 & 8947 \\
\hline \multirow[t]{5}{*}{ International } & $\mathrm{MU}$ & 29,382 & 11,924 & 22,486 & 27,258 & 8321 & 20,954 & 991 & 229 & 604 \\
\hline & FM & 1933 & 543 & 1173 & 3489 & 596 & 1787 & 350 & 95 & 222 \\
\hline & MU-FM & 16,240 & 6031 & 11,710 & 20,400 & 5531 & 14,131 & 1214 & 291 & 776 \\
\hline & MU Group & 47,555 & 18,497 & 35,369 & 51,147 & 14,448 & 36,872 & 2555 & 614 & 1602 \\
\hline & $\begin{array}{l}\text { MU Group + Alliance } \\
\text { Partners }\end{array}$ & 75,554 & 28,930 & 55,450 & 84,728 & 23,934 & 60,809 & 4397 & 1033 & 2711 \\
\hline
\end{tabular}




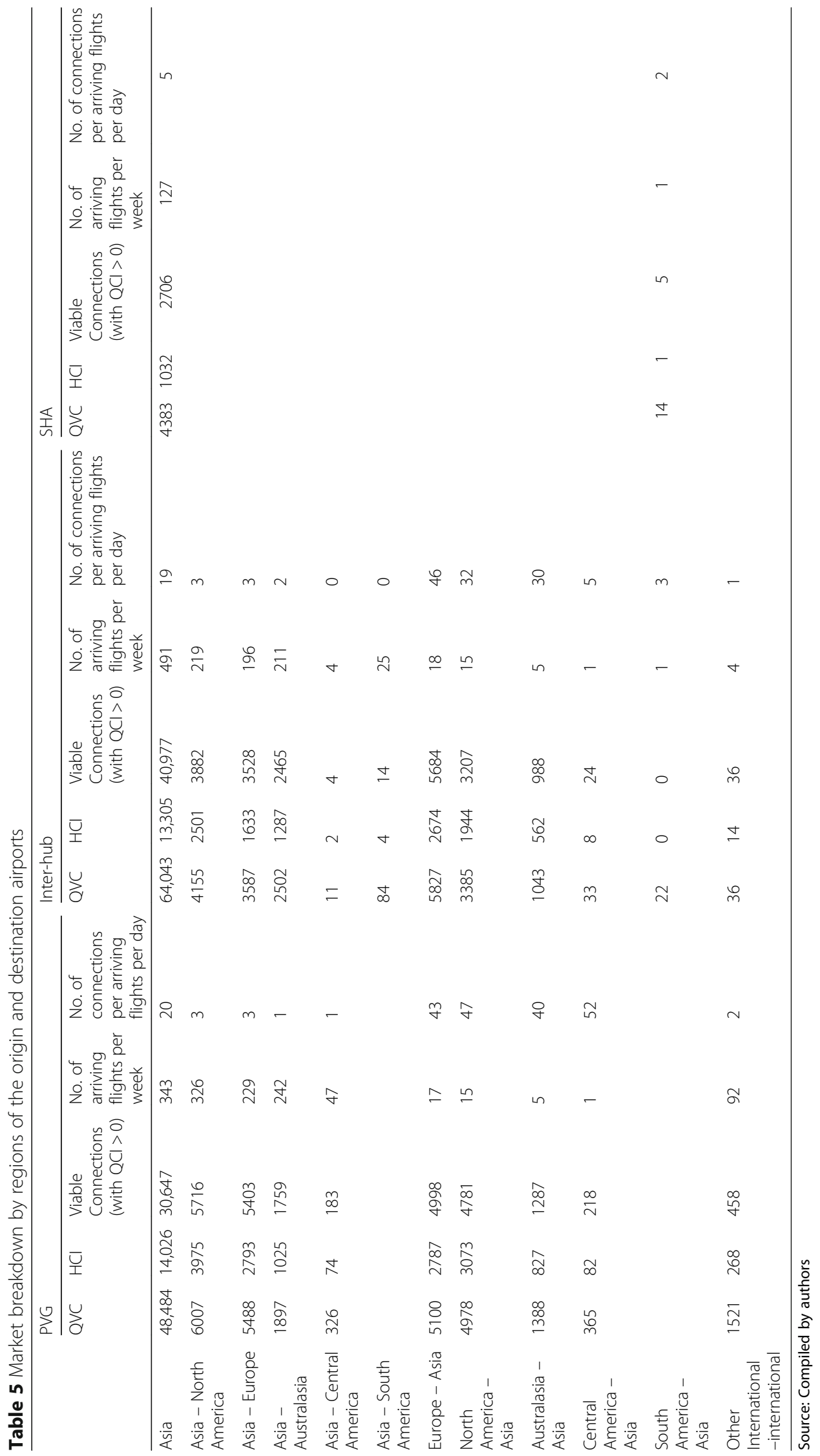


suffer from the inter-hub connection in a short/medium term. Meanwhile, more slots will be released in Pudong when the fifth runway and the additional satellite concourse are put into use. It can be expected that a larger proportion of those slots will be assigned to international flights over the coming years. Furthermore, the new international slot allocation policy forced Chinese carriers to end their monopolistic positioning on major international routes by now competing with other Chinese and international carriers and to also operate on secondary routes and new routes [6]. Hence, the key challenge for China Eastern Airlines will be network expansion and hub connectivity optimization. Code sharing with other Chinese airlines are necessary to enhancing its connectivity on the domestic market, particularly after China Southern Airlines left SkyTeam Alliance.

\section{Conclusion}

This research aims at assessing the hub connectivity of China Eastern Airlines under a dual-hub configuration in Shanghai. Indicators proposed by Li et al. were applied and modified to investigate both the quantity and quality of viable connections. The penalty factor in the previous study was considered irrelevant to either the ground travel time or the total perceived flight time, and removed in this research. Moreover, the weekly frequency was taken into account by the mechanism when weekly data applies. Hence, the Hub Connectivity Indicator $(\mathrm{HCI})$ was derived by summing the quality of all viable connections. The research scope included overnight connections and international-international inter-hub transfers to investigate Shanghai's potential to become a gateway hub.

The empirical analysis addressed that the biggest constraint of MU Group's dual-hub situation lies in Shanghai's location and the restricted transfer options for international routes. Although airports in China were heavily connected with and circled around Shanghai, the prolonged detour transferring via the east-coast part of China made it less appealing for domestic connections. In general, MU performed better than its subsidiary under the dual-hub operation, as the operation scale of FM mainly targeted at the mainland of China with limited international flights. MU Group benefited from the strong network of China Southern Group on domestic market. With China Southern Airlines Group left SkyTeam in 2019, MU Group lost its one and the only alliance partner on the domestic market, and $78 \%$ of QVC and $65 \%$ of HCI. Consequently, code sharing with other Chinese airlines outside the alliance will become one of the solutions for MU Group to enhancing its connectivity on the domestic market.

The empirical study of MU Group also pointed out the shortcoming of operating at two hubs in the same catchment area, where the quality of connectivity of inter- hub connections cannot be maintained as high as a singlehub transfer. Overall, single hub transfer via Pudong was more efficient and convenient for passengers on both domestic and international routes. However, the inter-hub connections tremendously enriched passengers choices by offering more opportunities to connect. Both single hub transfers and inter-hub ones showed strong directionality in terms of transfer opportunities. The limited number of international flights cannot provide equivalent connections for domestic ones. To fulfil its goal of becoming an international gateway in China, hub airlines and airports in Shanghai need to pay close attention to international transfers, in order to further strengthen Shanghai's hub connectivity and the competitiveness of domestic airlines on the international aviation market.

It is also worth mentioning that the real disutility to interconnect within a multi-airport system may be different from the value captured by the changes in connectivity. Future work could explore a wider aspect of passenger willingness that reflect further attributes of airport hub connectivity.

Last but not the least, it would be worthwhile to explore how universal those findings are by conducting a similar analysis for multi-airport systems in Europe and other regions to obtain a better understanding of hub connectivity in multi-hub circumstance. The methodology and subsequent results proposed in this analysis will become important references for European transport studies.

\section{Endnotes}

${ }^{1}$ An extra 30 -min is added to transfer time when terminal changes between two connecting flights.

${ }^{2}$ VariFlight is a Chinese based information technology company, specialising in the civil aviation data services.

${ }^{3}$ International flights in this research include regional flights to/from Hong Kong, Macau and Taiwan, where administrative work is required by the Immigration Inspection.

${ }^{4}$ Domestic flights refer to flights whose origin and destination locate in mainland China.

${ }^{5}$ Only connections involving at least one segment operated by the corresponding airline (either MU or FM) are included in the performance of alliance partners.

${ }^{6}$ DLC, CAN, SZX and PEK refer to the IATA airport code for Dalian, Guangzhou, Shenzhen and Beijing.

${ }^{7}$ XIY, XMN and CTU refer to the IATA airport code for Xi'an, Xiamen and Chengdu.

Acknowledgements

This research is supported by Civil Aviation Flight University of China (Q2018147).

Funding

This research is supported by Civil Aviation Flight University of China (Q2018-147). 


\section{Availability of data and materials}

Flight schedule data involved in this research can be found at http://www. variflight.com.

\section{Authors' contributions}

HY analysed the data; WL contributed materials/analysis; HY and WL wrote the paper. Both authors read and approved the final manuscript.

\section{Competing interests}

The authors declare that they have no competing interests.

\section{Publisher's Note}

Springer Nature remains neutral with regard to jurisdictional claims in published maps and institutional affiliations.

Received: 4 November 2018 Accepted: 7 May 2019

Published online: 15 May 2019

\section{References}

1. Boeing (2018). Commercial market outlook (2018-2037). https://www.boeing. com/resources/boeingdotcom/commercial/market/commercial-marketoutlook/assets/downloads/2018-cmo-09-11.pdf. Accessed 20 Feb 2019.

2. Bootsma, P. D. (1997). Airline flight schedule development: Analysis and design tools for European hinterland hubs. Utrecht: University of Twente.

3. Burghouwt, G., \& de Wit, J. (2005). Temporal configurations of European airline networks. J Air Transp Manag, 11(3), 185-198.

4. Burghouwt, G., \& Veldhuis, J. (2006). The competitive position of hub airports in the transatlantic market. J Air Transportation, (1), 11

5. Butler, V. \& Poole, R. W. (2008). Increasing Airport Capacity Without Increasing Airport Size. research.policyarchive.org/5778.pdf. Accessed 21 Feb 2019.

6. CAAC (2018). Slot allocation rules on international market. http://www.caac.gov.cn/ XXGKXXXGK/ZFGW/201805/P020180514396815036835.pdf. Accessed 21 Feb 2019.

7. Cascetta, E., \& Coppola, P. (2015). New high-speed rail lines and market competition short-term effects on services and demand in Italy. Transp Res Rec, 2475, 8-15.

8. Chow, C. K. W., \& Tsui, W. H. K. (2017). Organizational learning, operating costs and airline consolidation policy in the Chinese airline industry. J Air Transp Manag, 63, 108-118.

9. Danesi, A. (2006). Measuring airline hub timetable co-ordination and connectivity: Definition of a new index and application to a sample of European hubs. Eur Transport, 34, 54-74.

10. Doganis, R., \& Dennis, N. (1989). Lessons in hubbing. Airl Bus, 42-47.

11. European Commission (2015). European observatory on airport capacity \& quality. https://ec.europa.eu/transport/sites/transport/files/modes/air/ airports/doc/tf3 final report.pdf. Accessed 21 Feb 2019.

12. Hosombat, W., Lei, Z., \& Fu, X. (2011). Development status and prospects for aviation hubs - a comparative study of the major airports in South-East Asia. Singapore Econ Rev, 56(4), 573-591.

13. Huang, J., \& Wang, J. (2017). A comparison of indirect connectivity in Chinese airport hubs: 2010 vs. 2015. J Air Transp Manag, 67, 29-39.

14. ITF. (2014). Expanding airport capacity in large urban areas. Paris: OECD Publishing.

15. Li, W., Miyoshi, C., \& Pagliari, R. (2012). Dual-hub network connectivity: An analysis of all Nippon airways' use of Tokyo's Haneda and Narita airports. $J$ Air Transp Manag, 23, 12-16.

16. Logothetis, M., \& Miyoshi, C. (2016). Network performance and competitive impact of the single hub e a case study on Turkish airlines and emirates. $J$ Air Transp Manag, 69, 1-9.

17. Martín, J. C., \& Voltes-Dorta, A. (2011). The dilemma between capacity expansions and multi-airport systems: Empirical evidence from the industry's cost function. Transp Res E, 47, 382-389.

18. Matsumoto, H., Burghouwt, G., De Wit, J., Veldhuis, J. (2009). Air network performance and hub competitive position: Evaluation of primary airports in east and Southeast Asia. https://www.researchgate.net/publication/228337290_Air_ Network_Performance_and_Hub_Competitive_Position_Evaluation_of_Primary_ Airports_in_East_and_Southeast_Asia. Accessed 25 Feb 2019.

19. Nayak, N. (2012). Estimation of the impact of single airport and multi-airport system delay on the National Airspace System using multivariate simultaneous models. http://scholarcommons.usf.edu/etd/4181. Accessed 23 Feb 2019 .
20. Redondi, R., Malighetti, P. \& Paleari, S. (2010). De-Hubbing cases and recovery patterns. S.I., Air Transport Research Society.

21. Shanghai Government. (2016). Shanghai Master Plan 2040. Shanghai: Shanghai Government.

22. Toh, M., 2018. China southern to leave SkyTeam. https://www.flightglobal.com/ news/articles/china-southern-to-leave-skyteam-453663/. Accessed 2 Mar 2019.

23. Veldhuis, J. (1997). The competitive position of airline networks. J Air Transp Manag, 3(4), 181-188.

24. Wu, W., \& Dong, Z. (2015). Exploring the geography of China's airport networks: A hybrid complex-network approach. London: Spatial Economics Research Centre.

25. Zhang, Y., Zhang, A., Zhu, Z., \& Wang, K. (2017). Connectivity at Chinese airports: The evolution and drivers. Transp Res A, 103, 490-508.

26. Zhu, Z., Zhang, A., \& Yahua, Z. (2017). Connectivity of intercity passenger transportation in China: A multi-modal and network approach. J Transp Geogr, 71, 263-276.

27. Zografos, K. G., Madas, M. A., \& Androutsopoulos, K. N. (2017). Increasing airport capacity utilisation through optimum slot scheduling: Review of current developments and identification of future needs. J Sched, 20(1), 3-24.

\section{Submit your manuscript to a SpringerOpen ${ }^{\circ}$ journal and benefit from:}

- Convenient online submission

- Rigorous peer review

- Open access: articles freely available online

- High visibility within the field

- Retaining the copyright to your article

Submit your next manuscript at $\boldsymbol{\nabla}$ springeropen.com 